\title{
СОСТАВЫ ПИРОПОВ ИЗ КИМБЕРЛИТОВ С РАЗНОЙ АЛМАЗОНОСНОСТЬЮ ТРУБКИ ЛУЕЛЕ (АНГОЛА)
}

\author{
А. С. Иванов ${ }^{1}$ Ж. Т. Феликс ${ }^{2}$ Ю. Б. Стегницкий ${ }^{1}$ \\ ${ }^{1}$ НИГП АК «АЛРОСА», г. Мирный \\ ${ }^{2}$ Горнорудное Общество Катока, Республика Ангола
}

Поступила в редакцию 7 мая 2018 г.

\begin{abstract}
Аннотация: приведен статистический анализ данных микрозондовых определений составов пиропов из кимберлитов разной алмазоносности трубки Луеле (Ангола). Выполнень пересчетьл составов пиропов на основные парагенетические группы составов по классификации Н. В. Соболева и кластерные группь Доусона. Установлена значимая корреляция парагенетических групп и кластерных групп составов пиропов с алмазоносностью трех разновидностей кимберлитов. Апробирован дополнительный $\mathrm{Mn}-\mathrm{Mg}$ критерий для оченки потенциальной алмазоносности кимберлитов на основе относительного подсчета зерен пиропов, составы которых попадают в область алмазоносного окна по содержанию в этих минералах окислов марганца и магния. Результатом данной работь является факт того, что для оценки ураганных содержаний алмазов в кимберлитах по составам пиропов ультраосновных парагенезисов работает также и критерий $\mathrm{Mn}-\mathrm{Mg}$ облака. На данном примере исследований доказано, что иентральная область проекции этого облака точек для составов пиропов, которые по марганцевому термометру благоприятна для совместной кристаллизации и сохранности алмаза попадает в область 0,4\% весовых содержаний для МnO и 20 \% весовых проиентов для $\mathrm{MgO}$. Отклонения проекции точек на бинарных диаграммах составов пиропов от выше указанных параметров содержания $\mathrm{MnO}$ и $\mathrm{MgO}$ определяется для таких зерен РТ параметрами не стабильными для массовой кристаллизащии с ними алмазов в мантийных породах.
\end{abstract}

Ключевые слова: кимберлит, пироп, алмаз.

\section{STRUCTURES PIROPS FROM KIMBERLITES WITH THE DIFFERENT DIAMONDS CONTENTS OF THE TUBE LUELE (ANGOLA)}

\begin{abstract}
: in work the statistical analysis of the made microanalysis definitions of structures pyrops from kimberlites of a different diamonds contents of a tube to Luele (Angola) is made. Recalculations of structures perops on the main paragenetic groups of structures on N.V. Sobolev's classifications and clusters groups of Dawson are executed. Significant correlation of paragenetic groups and clusters groups of structures pyrops with an diamonds contents of three versions of kimberlites is established. Additional Mn-Mg criterion for an assessment of a potential diamonds contents of kimberlites on the basis of relative calculation of grains pyrops which structures get to area of a diamondiferous window according to the contents in these minerals of oxides of manganese and magnesium is approved. The fact that for assessment of storm content of diamonds in kimberlites on structures of pyropes of the ultramain paragenesis works as well criterion of $\mathrm{Mn}-\mathrm{Mg}$ of a cloud is result of this work. On this example of researches it is proved that the central region of a projection of this cloud of points for structures of pyropes which on the manganese thermometer it is favorable for a collateral crystallization and safety of diamond gets to the area of 0,4\% of weight contents for $\mathrm{MnO}$ and $20 \%$ of weight percents for $\mathrm{MgO}$. Deviations of a projection of points on binary charts of structures of pyropes from above the specified parameters of maintenance of $\mathrm{MnO}$ and $\mathrm{MgO}$ decides for such PT grains by parameters not stable for a mass crystallization of diamonds on them in mantle.
\end{abstract}

Keywords: kimberlite, pyrop, diamond.

Кимберлитовая трубка Луеле, обнаруженная геологами ГРО «Катока», располагается на северовостоке Анголы в 20 км от месторождения Катока и характеризуется промышленным содержанием алма- зов. В настоящее время на этом месторождении проводятся геологоразведочные работы.

Из трех разновидностей алмазоносных кимберлитов трубки Луеле (ураганно алмазоносные - >3 кар./т; 

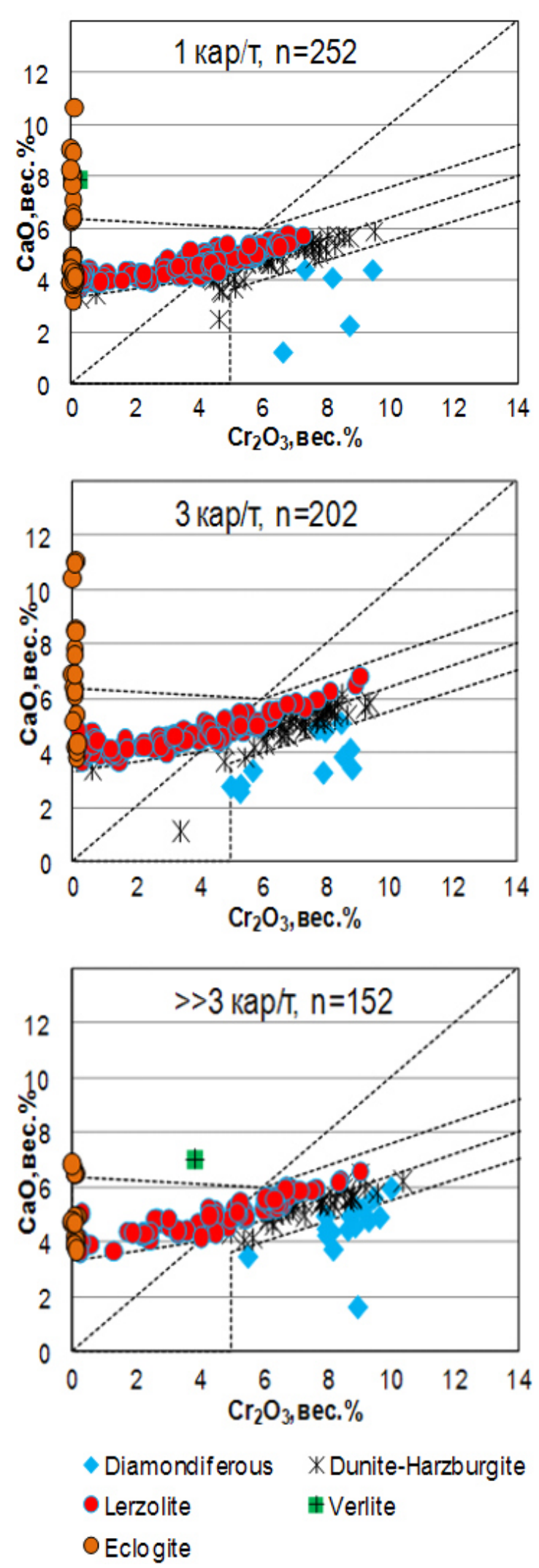

Puc. 1. Диаграммы Н. В.Соболева составов пиропов из трех степеней алмазоносности кимберлитов.

высоко алмазоносные - 3-1 кар./т; средне алмазоносные - 1-0,25 кар./т) были отобраны случайные выборки зерен пиропов. Из кимберлитов с высокой алмазоносностью отобрано 202 зерна, со средней алмазоносностью 252 зерна пиропа и из ураганно алмазоносных были выбраны 152 зерна. Всего в интерпретации данных использовано 605 зерен пиропов. Пиропы были препарированы в три шашки и проанализированы на микроанализаторе JXAJXA-8230 в Центральной аналитической лаборатории (ЦАЛ) научно-исследовательского геологического предприятия (НИГП) акционерной компании «АЛРОСА».

Цель данной работы - выяснение взаимозависимости определенных парагенезисов и составов класстерных групп пиропов с алмазоносностью разных типов кимберлита.

Для выяснения химического разнообразия трех выборок составов пиропов были построены диаграммы Н. В.Соболева [1] и подсчитаны соотношения групп основных парагенезисов (рис. 1, 2).

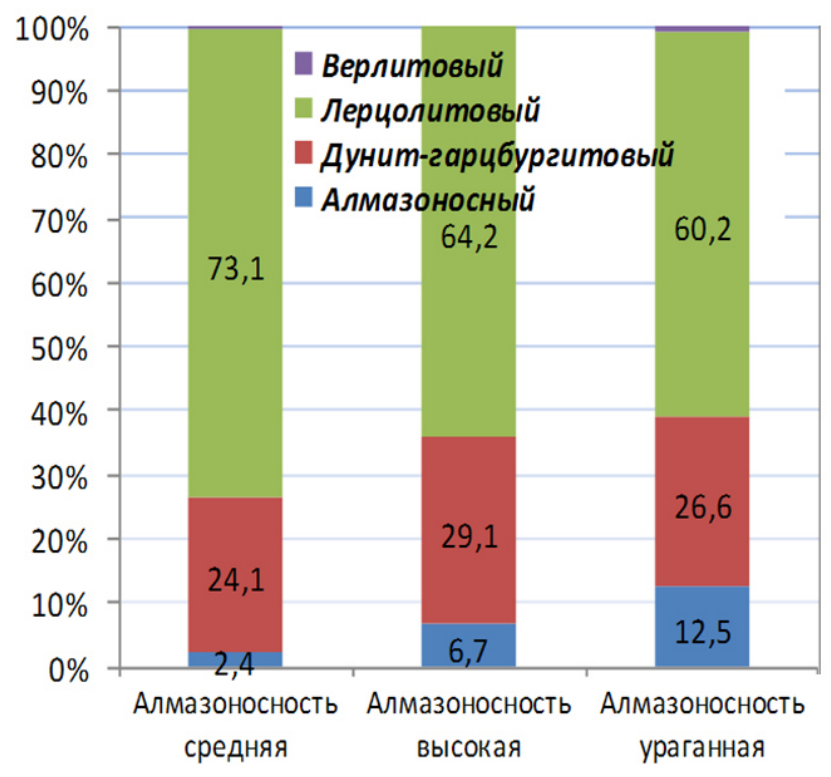

Puc. 2. Гистограммы основных парагенезисов пиропов по Н. В. Соболеву (в отн.\%) из трех разных степеней алмазоносности блоков кимберлитов тр. Луеле.

В составах пиропов из кимберлитов трех степеней алмазоносности был определен никель. По $\mathrm{Ni}$ геотермометру Гриффина [2] были рассчитаны соотношения температур кристаллизации пиропов из кимберлитов трех степеней алмазоносности тр. Луеле (рис. 3).

По алгоритмам, предложенным в работе [3] были рассчитаны кластерные группы составов пиропов Dawson J.B. для трех степеней алмазоносности кимберлитов (табл. 1, рис. 4).

Для составов низко хромистых высоко титанистых пиропов группы G2 с увеличением степени алмазоносности кимберлитов количество зерен в выборках убывает, а количество зерен группы G10 высоко хромистых низко титанистых составов пиропов растет. Титан в кимберлите обратно коррелируется с продуктивностью на алмазы, что можно проверить и на химическом составе кимберлита.

ВЕСТНИК ВГУ. СЕРИЯ: ГЕОЛОГИЯ. 2018. № 2 


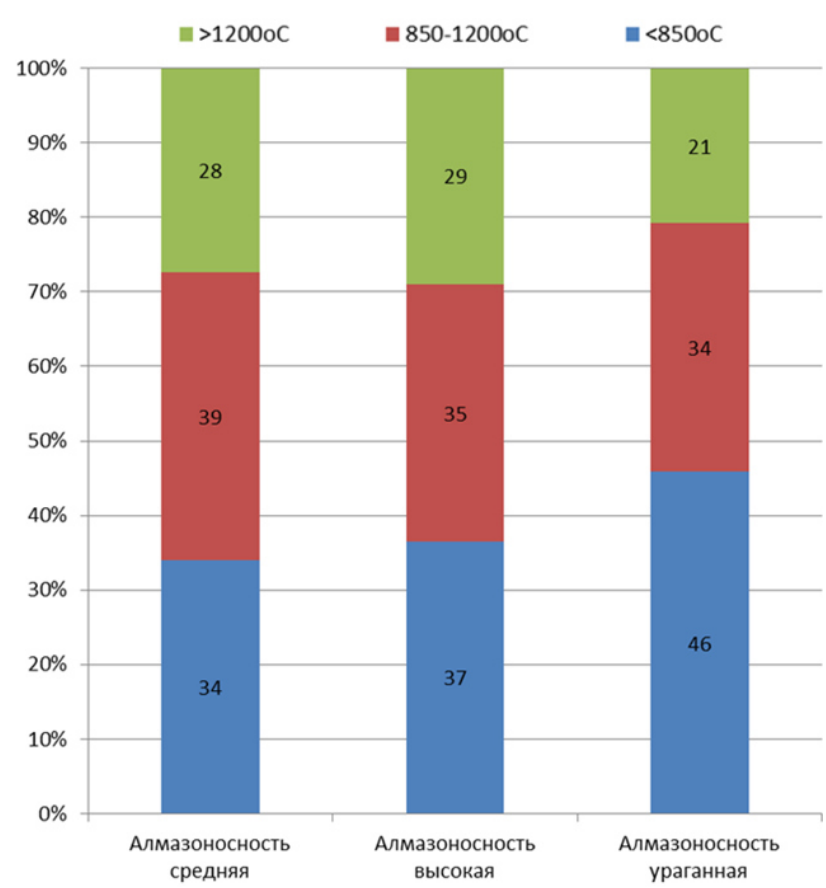

Puc. 3. Гистограммы условий формирования только Crпиропов $\left(\mathrm{Cr}_{2} \mathrm{O}_{3}>1,5 \%\right)$ (Ni геотермометр Гриффина) из кимберлитов трех степеней алмазоносности тр. Луеле.

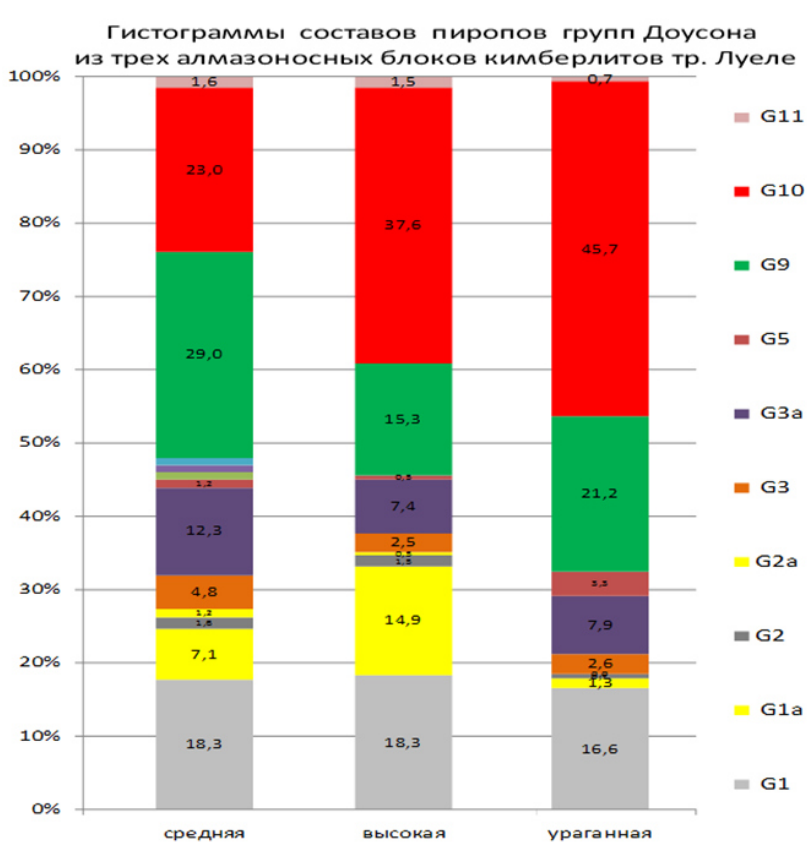

Puc. 4. Гистограмма частот распределения гранатов по кластерным группам Доусона [3].

Частоты встречаемости кластерных групп по Доусону [3]

Таблица 1 в трех блоках кимберлитов тр. Луеле разной степени алмазоносности

\begin{tabular}{|c|c|c|c|c|c|c|c|c|c|c|c|c|}
\hline Алмазоносность & G1 & G1a & G2 & G2a & G3 & G3a & G4 & G5 & G9 & G10 & G11 & Всего \\
\hline Средняя & 18,3 & 7,1 & 1,6 & 1,2 & 4,8 & 12,3 & 0,0 & 1,2 & 29,0 & 23,0 & 1,6 & 100 \\
\hline Высокая & 18,3 & 14,9 & 1,5 & 0,5 & 2,5 & 7,4 & 0,0 & 0,5 & 15,3 & 37,6 & 1,5 & 100 \\
\hline Ураганная & 16,6 & 1,3 & 0,7 & 0,0 & 2,6 & 7,9 & 0,0 & 3,3 & 21,2 & 45,7 & 0,7 & 100 \\
\hline
\end{tabular}

Группа G1 - это низко и средне хромистые пиропы с содержанием окиси титана от 0,3 до $0,6 \%$. Группа G2 - с окисью титана более 0,6\%. Группа G9 почти как группа G1, но титан там менее $0,3 \%$. Группа G10 это высокохромистые пиропы с окисью титана не более $0,3 \%$.

Для низко хромистых составов пиропов кластерные группы Доусона G1, G2, G3 разделены по содержанию окиси натрия. Составы зерен пиропов в этих группах, которые содержат $\mathrm{Na}_{2} \mathrm{O}$ более $0,07 \%$ весовых, в названиях имеют значок «а» G1a,G2a,G3a. Такие группы рядом авторов [4] относят к алмазоносным парагенезисам (рис. 5).

В данной работе рассмотрен простой способ определения степени продуктивности кимберлитов, который основан на проекции фигуративных точек анализов составов пиропов в крест пресечения бинарной диаграммы с содержаниями $\mathrm{MgO}=20,0$ вес.\% и $\mathrm{MnO}=0,4$ вес.\% [5]. Критерий основан на том факте, что составы пиропов ультраосновных парагенезисов из большинства промышленных кимберлитов на эту диаграмму проектируются в виде облака точек анализа в указанный центр пересечения их составов. В связи с этим предложено алмазоносное окно на бинарной диаграмме в координатах $\mathrm{MgO}-\mathrm{MnO}$ $\mathrm{MnO}$ (рис. 6).

Определение количества зерен и их относительного содержания составов пиропов в алмазоносном, и не алмазоносном окне удобно рассчитывать путем включения фильтров в таблицах офисной цифровой программы Excel. По содержанию $\mathrm{MnO}$ в интервале от 0,3 вес.\% до 0,5 вес. $\%$ и по $\mathrm{MgO}$ от 19,0 вес.\% до 21,0 вес.\%. Далее добавим в таблицу новую переменную с названием этих групп, и выбираем сводные таблицы со следующими содержанииями, а также строим гистограммы относительного содержания составов пиропов в алмазоносном окне и за его пределами. Пример приведен на (рис. 7), где представлены гистограммы частот встречаемости пиропов в алмазоносном и не алмазоносном окне ряда кимберлитовых тел Анголы. Кимберлитовые тела, которых в алмазоносном окне более $50 \%$ из случайной выборки зерен пиропов можно относить к потенциально алмазоносным кимберлитам. 

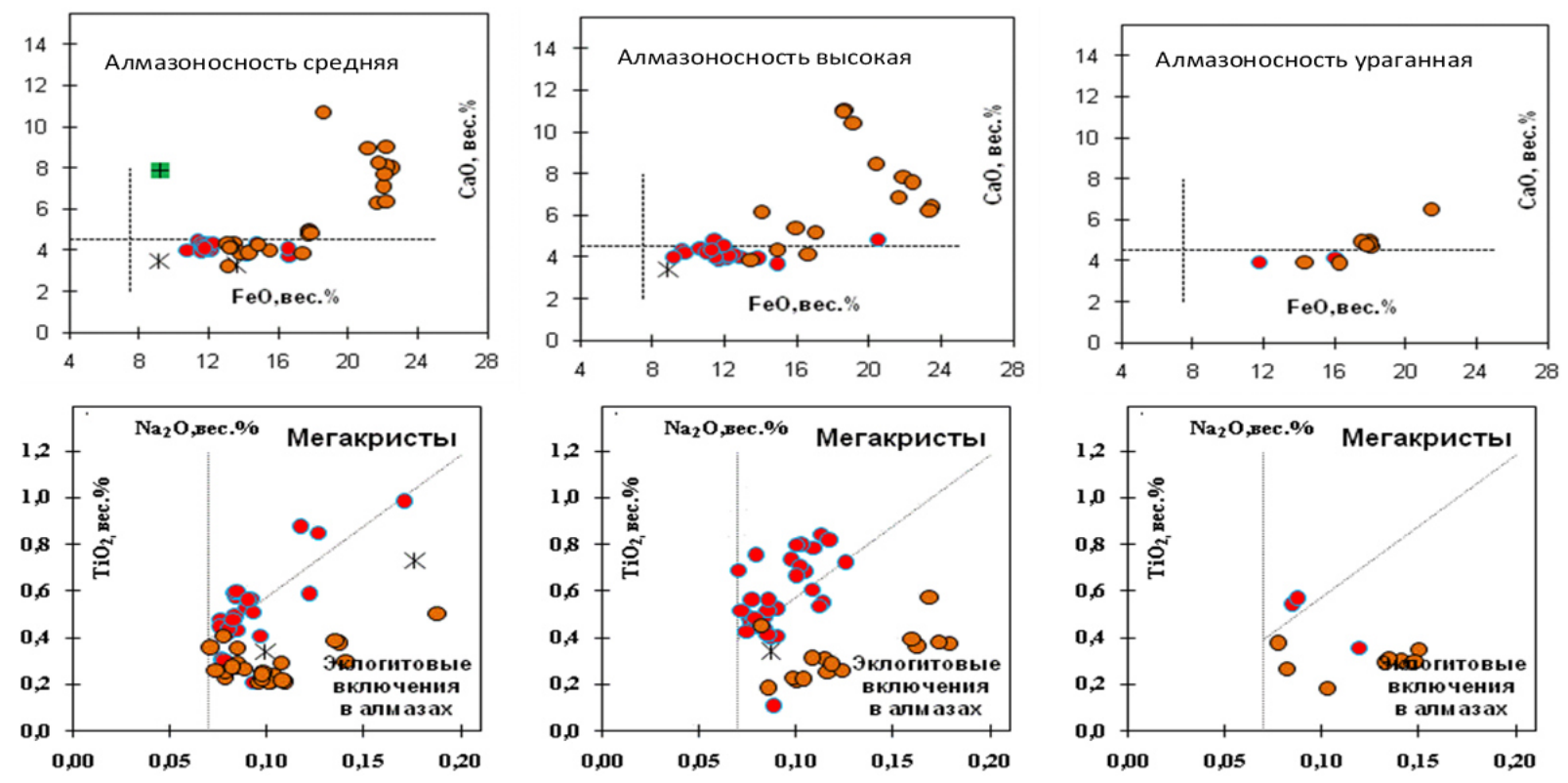

Pис. 5. По две диаграммы в столбике для алмазоносных вебстеритовых и эклогитовых парагенезисов составов пиропов из трех блоков кимберлитов тр. Луеле, группы G1a, G2a, G3a.
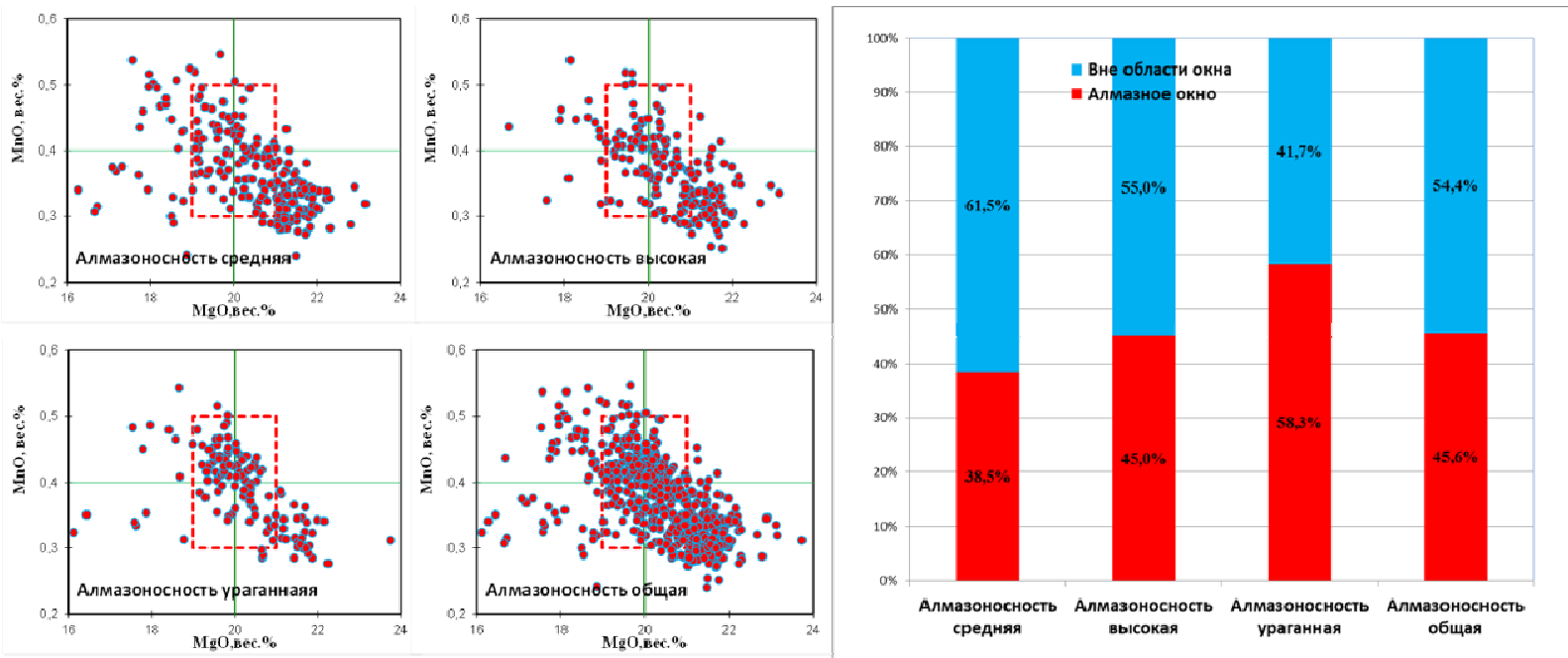

Puc. 6. Диаграммы и гистограммы количественного распределения в алмазоносном окне $\mathrm{MgO}-\mathrm{MnO}$ составов пиропов из кимберлитов с различной степенью алмазоносности тр. Луеле.

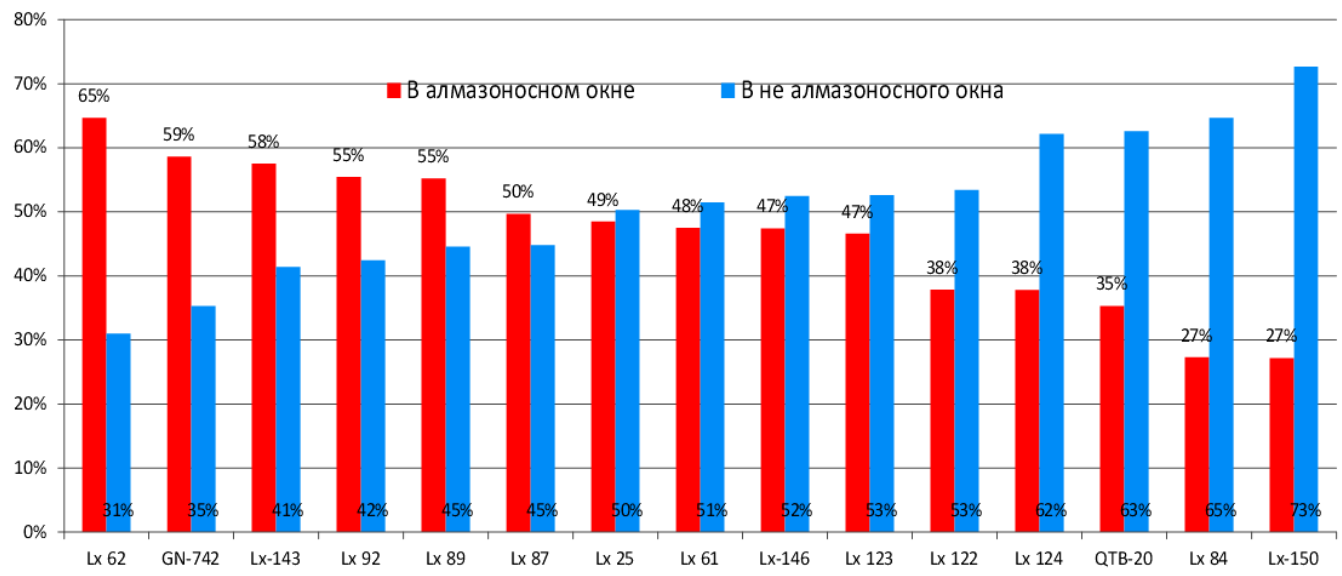

Puc. 7. Гистограммы относительных содержаний составов пиропов в алмазоносном и не алмазоносном окне окислов магния и марганца для ряда кимберлитовых тел Анголы. 
Таким образом, для выяснения химического разнообразия составов пиропов из кимберлитов с разной алмазоносностью хорошо работает критерий Н. В. Соболева [1], по которому и подсчитаны соотношения групп основных парагенезисов. Пиропов алмазоносных парагенезисов по данному критерию из кимберлита с ураганной алмазоносностью более $12,5 \%$.

Соотношения температур кристаллизации пиропов по $\mathrm{Ni}$ геотермометру Гриффина [2] по составам пиропов с содержаниями окиси хрома в них более 2 весовых процентов в алмазоносном коридоре отвечает последовательности кимберлитов разных ступеней алмазоносности (рис. 3). Низкое содержание зерен пиропов (от 19 до $36 \%$ ) в алмазоносном коридоре Гриффина можно объяснить тем, что в общей алмазоносности трех блоков кимберлитов большую долю вносят алмазоносные вебстеритовые и эклогитовые их парагенезисы. Составов пиропов из алмазоносных вебстеритовых и эклогитовых парагенезисов в выборках не более 10 \% и их относительно больше в кимберлитовом блоке с ураганной алмазоносностью. Характерной особенностью низко хромистых групп составов пиропов является то, что с повышением степени алмазоносности кимберлитов, меньше встречаются в выборках зерна пиропов группы G2 с повышенными значениями окиси титана (табл. 1, рис. 4).

По набору кластерных групп Доусона [3] также отмечена положительная корреляция с частотой встречаемости составов пиропов определенных класстерных групп. Пиропы из кимберлитов с ураганной алмазоносностью содержат самый высокий процент (45 \%) лиловых пиропов группы G10.

Научно-исследовательское геологическое предприятие (НИГП) АК «АЛРОСА» (ПАО), г. Мирный

Иванов Александр Сергеевич, кандидат геологоминералогических наук, ведущий научный сотрудник E-mail: IvanovAS@alrosa.ru

Тел.: + 79142524307

Стегниикий Юрий Борисович, кандидат геологоминералогических наук, заведующий лабораторией ЛИЗТ E-mail: StegnitskiyYuB@alrosa.ru

Тел.: + 7914258990

Горнорудное Общество Катока, г. Луанда Республика Ангола

Жоао Тунга Феликс, кандидат экономических наук, начальник геологического департамента E-mail:felix@catoca.com
Для оценки ураганных содержаний по составам пиропов работает также и критерий $\mathrm{Mn}-\mathrm{Mg}$ облака [5]. [5]. Центральная область проекции этого облака точек для составов пиропов, которые по марганцевому термометру благоприятна для совместной кристалллизации и сохранности алмаза попадает в область 0,4 $\%$ весовых содержаний для $\mathrm{MnO}$ и $20 \%$ весовых процентов для $\mathrm{MgO}$. Отклонения проекции точек на бинарных диаграммах составов пиропов от выше указанных параметров содержания $\mathrm{MnO}$ и $\mathrm{MgO}$, очевидно, определяется для таких зерен РТ параметрами не стабильными для массовой кристаллизации с ними алмазов в мантийных породах.

\section{ЛИТЕРАТУРА}

1. Соболев, Н. В. О минералогических критериях алмазоносности кимберлитов / Н. В. Соболев // Геология и геофизика. - 1971. - №3. - С.70-80

2. Grifin, W. L. Trace elements in indicator minerals: Area selection and target evaluation in diamond exploration / W. L. Grifin, C. G. Ryan //. J. Geochem. Explor. - Vol. 53. - P. 311357.

3. Dawson, J. B. Statistical classification of garnets from kimberlites and xenoliths / J. B. Dawson, W. E. Stephens // J. Geol. - 1975. - Vol. 83. - № 5. - P. 589-607.

4. Герни, Дж. Дж. Геохимическая корреляция между минералами кимберлитов и алмазами Кратона Калахари / Дж. Дж. Герни, Р. О. Мур // Геология и геофизика. - 1994. С.12-24.

5. Иванов, А. С. Новый критерий алмазоносности кимберлитов / А. С. Иванов // Труды ХІІ Всероссийской (с международным участием) Ферсмановской сессии. - Апатиты: КНЦ РАН. - 2015. - С.268-270.

Scientific and research geological enterprise (NIGP) AK ALROSA (PAO), Mirny

Ivanov A. S., candidate of Geological Mineralogical Sciences, leading researcher

E-mail: IvanovAS@alrosa.ru

Tel.: +79142524307

Stegnitsky Yu. B., candidate of Geological Mineralogical

Sciences, head of laboratory LIZT

E-mail: StegnitskiyYuB@alrosa.ru

Tel.: + 7914258990

Mining Society Catoca, Luanda Republic of Angola

Joao Tunga Felix, doctor of Economics Sciences, head of Geological Department

E-mail:felix@catoca.com 